\title{
Flower Pollination Algorithm Based PDFF Controller for a Two- Area Interconnected Thermal Power System with Gas / Diesel Units
}

\author{
G. Ganesan Subramanian ${ }^{1, *}$, I. A.Chidambaram ${ }^{1}$ and J. Samuel Manoharan ${ }^{2}$ \\ ${ }^{1}$ Department of Electrical Engineering, Annamalai University, Annamalainagar, Tamil Nadu \\ ${ }^{2}$ Department of Electronics and Communication Engineering, Bharathiyar College of Engineering and \\ Technology, Karaikal, Pondicherry
}

\begin{abstract}
This paper presents a new approach for designing a Pseudo Derivative Feed Forward (FDFF) controller for the load- frequency control of the interconnected power system comprising Thermal power system and Gas / Diesel power plants. The proposed PDFF controller is designed to improve the dynamic performance of the frequency and tie line power under a sudden load disturbance in an area with the computation of Ancillary Service Requirement Assessment Indices (ASRAI). The PDFF controller is optimized using Flower Pollination Algorithm (FPA) which is based on the quality of pollination process of flowers. The optimized PDFF controller is implemented to bring back the frequency to stable state and the net interchanges to their desired values for each control area in the shortest possible time based on the settling time and peak over shoot concept of control input deviations of each area. Simulation result reveals that the interconnected thermal power system with Gas power plant ensures a better dynamic and steady state performance than that of the system incorporated with Diesel power plant.
\end{abstract}

Keywords: Flower Pollination Algorithm (FPA), Load- Frequency Control (LFC), Pseudo Derivative Feed Forward Controller (PDFF).

\section{INTRODUCTION}

Load-Frequency Control (LFC) is of importance in electric power system design and operation. Frequency changes in large scale power systems have high impact resulting from the imbalance between the electrical load and the power supplied by connected generators [1]. Therefore LFC is one of the important power system control problems which requires more attention and so there have been considerable research works in progress from several decades back [2-6]. With the LFC the power system operation and control can be made better ensuring more reliable and secured operation even though increasing power requirement scenario exists.

The main objective of the LFC in an interconnected power system is to maintain the frequency of each area within limits and to keep the tie-line power flows within some pre-specified tolerances. A well designed and operated power system must cope with changes in the load and with system disturbances and it should provide acceptable high level of power quality. With the increase in size and complexity of electric demands, more sophisticated control methodologies have to be designed and implemented in ensuring a better steady state control and to enhance a better dynamic

*Address correspondence to this author at the Department of Electrical Engineering, Annamalai University, Annamalainagar, Tamil Nadu;

E-mail: g.ganeshsubramanian@yahoo.com response of the power system [7]. So load-frequency has to incorporate necessary intelligent systems that combine control operates with a response time of a few seconds to knowledge, techniques and mythologies from various keep system frequency stable.

Literature survey shows that, most of the studies concerned with LFC of interconnected power systems pertain to tie-line bias control strategy [2-7]. In many reported works, various control schemes based on decentralized Automatic Generation Control (AGC) strategy has been adopted for solving the LFC problems $[7,8]$ which is an ancillary service that plays principal role to maintain the electric system reliability and to improve the power quality in the power system operation [8].

However, governor is introduced into action and generator output is increased for larger mismatch. Now here the equilibrium point is obtained when the newly added load is distracted by reducing the power consumed by the old load and the increased generation by the governor action. Thus, there is a reduction in amount of kinetic energy which is extracted from the system to a large extent, but not totally. So the frequency decline still exists for this category of equilibrium. Whereas for this case it is much smaller than the previous one mentioned above. This type of equilibrium is generally obtained within 10 to 12 seconds just after the load addition. And this governor action is called primary control. Science after the introduction of governors action the system frequency 
is still different its predefined value, by another different control strategies it is needed the frequency to bring back to its predefined value. Conventional ProportionalIntegral (PI) Controllers which are referred as secondary control have been adopted to bring back the deviated system frequency to its predefined value or to zero. Supplementary controllers are designed to regulate the area control errors to zero effectively. Even in the case of small load disturbances and with the optimised gain for the supplementary controllers, the power frequency and the tie-line power deviations persist for a long duration. In these situations, the governor system may no longer be able to absorb the frequency fluctuations due to its slow response [7]. As a result of sudden power demands the power generations must change accordingly to match the load perturbations.

In a two area interconnected power system, where the two areas are connected through tie lines, the control area are supplied by each area and the power flow is allowed by the tie lines among the areas. Each output frequency finds the information about its own area and the tie line power deviation finds the information about the other areas. The main function of $A G C$ is to control load frequency and tie line power during load disturbance. So the error signals of frequency and tie line power are used as design criteria to tune the $\mathrm{PI}$ controller. The error inputs to the controllers are the respective area control errors $\left(A C E_{i}\right)$ given by [7]

$$
A C E_{i}=\beta_{i} \Delta F_{i}+\Delta P_{\text {tie } i, j}
$$

The control inputs of the power system u1 and u2 with PI structure are given by Eqs. (2) and (3).

$$
\begin{aligned}
& u_{1}=K_{P 1} A C E_{1}+K_{I 1} \int A C E_{1} d t \\
& u_{2}=K_{P 2} A C E_{2}+K_{I 2} \int A C E_{2} d t
\end{aligned}
$$

In this study, FPA is used to tune the PI controller for a two area thermal-diesel interconnected power system. Proportional gain constant $\left(\mathrm{K}_{\mathrm{Pi}}\right)$ and Integral gain constant $\left(\mathrm{K}_{\mathrm{ii}}\right)$, are considered as variables describing a population defined in an FPA. FPA requires an objective function which uses the design criteria to calculate the flower constancy of the defined population. An objective function is created which uses the variables of the population from FPA, passes through a model containing two area power system and obtains the error signals frequency $\left(\Delta F_{i}\right)$ and tie line $\operatorname{power}\left(\Delta P_{\text {tie, }, i, j}\right)$. The performance of these responses is measured using performance functions such as Integral of Squared Error (ISE) given by Eqn (4) [7].

$$
J=\int_{0}^{t_{\text {sing }}}\left[\left(\beta_{1} \Delta F_{1}\right)^{2}+\left(\beta_{2} \Delta F_{2}\right)^{2}+\Delta P_{\text {tie }}^{2}\right] d t
$$

Figure 1 shows a two area power system where each area supplies to its own area and the power flow between the areas are allowed by the tie line.

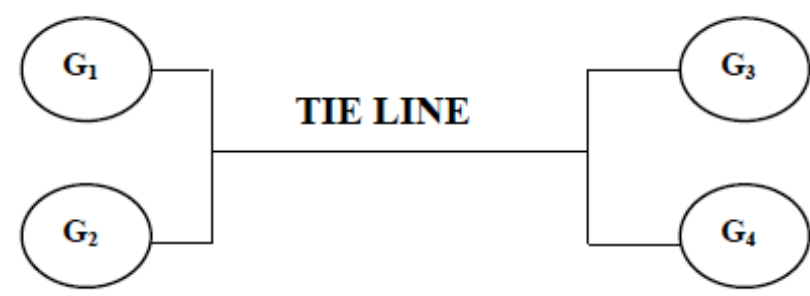

Figure 1: Two area interconnected power system.

The LFC design methodologies implemented so far mainly aim for the frequency stabilization and the ensuring zero ACE in each control area. In this pattern, the ACE control may conflict with the system frequency recovery even though optimal decentralized controllers are implemented. In view of the drawback in the restructured scenario this paper proposes a design methodology by incorporating PDFF Controller and comparative study of Thermal - Diesel unit $[9,10]$ and Thermal - Gas system unit $[11,12]$ along with the twoarea thermal power system. Various control methodologies [5-8] were adopted to tune the Proportional and Integral Controllers (PI controllers) like bacterial foraging technique, ant, bee colony algorithms and due to computational complexity those algorithms are found to inferior and a new natureinspired algorithm based on the characteristics of pollination process of flowers plants namely Flower Pollination Algorithm (FPA) has been proposed. This algorithm is one of the most promising less computational complex solution methodologies [13-18]. From the biological evolution point of view, the objective of the flower pollination is the survival of the fittest and the optimal reproduction of plants in terms of numbers as well as the fittest. The basic idea of flower pollination in the context of bees and clustering was investigated before, but in this paper discusses the completely new optimization strategy solely based on the flower pollination characteristics.

This paper proposes a conceptually computational methodology for ensuring better steady state response 
of the system. In this study without and with the incorporation of the Thermal - Gas and Thermal Diesel system to the two-area thermal restructured power system has been considered for poolco, bilateral and contract violation transactions. From the simulated results it is observed that the system with HDGT units ensures improved steady state parameters which provides and ensures a good margin of stability.

\section{MODELLING OF DIESEL POWER PLANTS}

The diesel electric power plants are used as Peak load plant and can be easily started or stopped at a short notice to meet the peak demand or as Mobile plants which can be mounted on trailers can be used for temporary or emergency purposes or as standby unit [9].

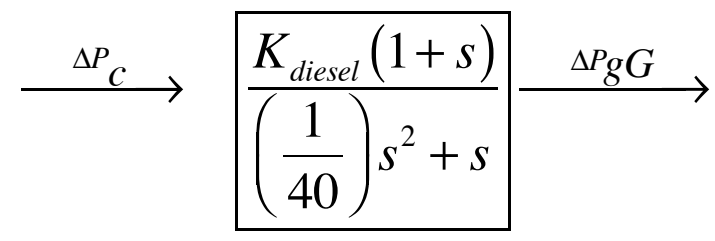

Figure 2: Transfer function representation of a diesel power plant.

The diesel power plant has the following drawbacks like high operating cost, high maintenance and lubrication cost, capacity is restricted, Noise problem, cannot supply overload, unhygienic emissions and the life of the diesel power plant is less (7 to 10 years) as compared to that of a steam power plant which has a life span of 25 to 45 years. The efficiency of the diesel plant decreases to less than $10 \%$ after its life period. So an attempt has been made to incorporate Heavy Duty Gas Turbine based power plant and will be discussed in the next Section.

\section{MODELLING OF GAS POWER PLANTS}

Gas turbines are important for power generation and as a result of increasing energy demand it is likely that their importance will grow in the coming decades.
A gas turbine can run on a range of fuels, natural gas from fossil fuel sources or from other gases like biogas and hydrogen gas. Systems that can work efficiently for a range of fuel compositions ensure power production less sensitive to political factors [11]. (Figure 3)

This paper proposes a conceptually computational methodology for ensuring better steady state response of the system. In this study without and with the incorporation of the Diesel power plant unit / HDGT unit with the two-area thermal power system has been considered. From the simulated results it is observed that the system with HDGT unit ensures improved steady state parameters which provides and ensures a good margin of stability.

\section{FLOWER POLLINATION ALGORITHM}

Yang [13] emulated the characteristic of the biological flower pollination in flowering plant to develop single objective FPA based on the rules listed as follows: (i) The global pollination processes are biotic and cross pollination through which the pollen transports pollinators perform the levy flight, (ii) Local pollination is viewed as abiotic and self pollination. (iii) Reproduction probability is considered as flower constancy which is proportional to the resemblance of the two flowers in concerned and (iv) The switching probability controlled both the local and global pollination $p \in[0,1]$. Local pollination can have fraction $p$ that is significant in the entire processes of the pollination because of physical proximity and wind. The plant can possess multiple flowers and every flower patch typically emits millions or even billions of pollen gametes in real life pollination practice $[14,15]$. To simplify the proposed algorithm development, it was assumed that each plant has a single flower and each flower emit only a single pollen gamete. This result is to the elimination of the need to differentiate pollen gamete, plant or solution to a problem. This means that a solution $x i$ to a problem is equivalent to a flower and pollen gamete. The major stages in the design of SFPA

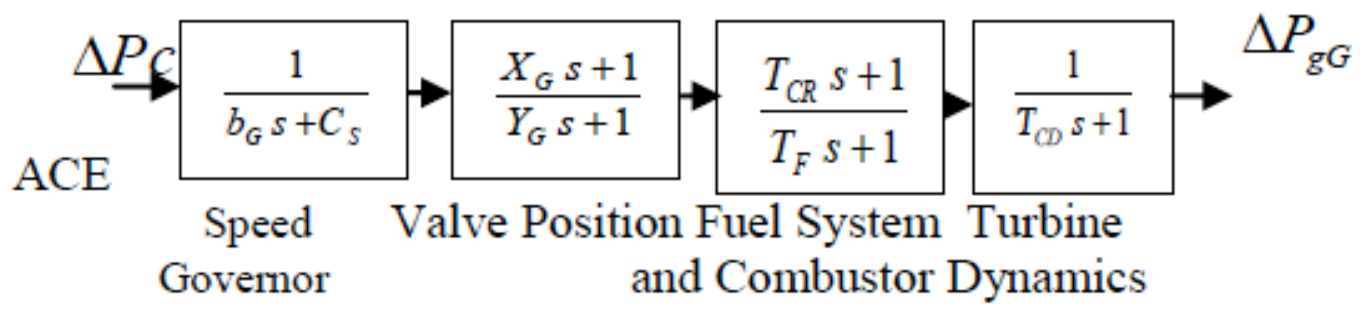

Figure 3: Shows the new transfer function LFC model with single stage reheat turbine in heavy duty gas system area are considered for deregulated environment. 
are global and local pollination. In the global pollination, the pollens of the flowers are moved by pollinators e.g. insects and pollens can move for a long distance since the insects typically fly for a long range of distances [16-18]. This process guarantees pollination and reproduction of the fittest solution represented as $\mathrm{g}^{*}$. The flower constancy can be represented as:

$x_{i}^{t+1}=x_{i}^{t}+L\left(x_{i}^{t}-g_{*}\right)$

where $x_{i}^{t}$ is the pollen $i$ or solution vector $x^{i}$ at iteration $t$, and $g_{*}$ is the current best solution found among all solutions at the current generation/iteration. The parameter $L$ is the strength of the pollination, which essentially is a step size. Since insects may move over a long distance with various distance steps, which is mimicked by levy distribution of flight $[14,15]$ and mathematically represented as;

$$
L \sim \frac{\lambda \Gamma(\lambda) \sin \left(\frac{\pi \lambda}{2}\right)}{\pi} \frac{1}{s^{1+\lambda}} \quad\left(s \ll s_{0}>0\right)
$$

where $\Gamma(\lambda)$ is the standard gamma function, and this distribution is valid for large steps $s>0$. The local pollination and flower constancy can be represented as;

$x_{i}^{t+1}=x_{i}^{t}+\varepsilon\left(x_{j}^{t}-x_{k}^{t}\right)$

where $x_{j}^{t}$ and $x_{k}^{t}$ represent pollen from different flowers of the same species of plant. Thus, mimic the flower constancy in a limited neighbourhood. The switch probability or proximity probability is used to switch between common global pollination to intensive local pollination. The effectiveness of the FPA can be attributed to the following two reasons: (i) Insect pollinators can travel in long distances which enable the FPA to avoid local landscape to search in a very large space (explorations). (ii) The FPA ensures that similar species of the flowers are consistently chosen which guarantee fast convergence to the optimal solution (exploitation). The proposed flower pollination algorithm for solving AGC application;
I. Step 1: Initialize the objective function as given in the equation (8).

II. Step 2: Initialize a population of $x=\left(x_{1}, x_{2} \ldots x_{N F}\right)$ flowers/pollen gametes with the population size of $N F \times N$. Where $N F$ is the number of flowers as 30 and $N$ is the dimension size depends on the number of controller gain values for each area in the two area system. In this study $N$ is equal to four because $\mathrm{PI}$ controller is used to in each area $\left(\mathrm{K}_{\mathrm{P} 1}, \mathrm{~K}_{11} \mathrm{~K}_{\mathrm{P} 2}, \mathrm{~K}_{12}\right)$ and calculate the Fitness for each solutions.

III. Step 3: Find the best solution to the initial population and define a switch probability $p \in[0$, 1] and define a stopping criterion (a fixed number of generations/iterations).

IV. Step 4: while ( $\mathrm{t}<$ Maximum Generation) for $\mathrm{i}=$ $1: \mathrm{n}$ (all $\mathrm{n}$ flowers in the population) if rand $<\mathrm{p}$, Draw a (d-dimensional) step vector $L$ which obeys a Levy distribution Global pollination has been done using equation (9). Else draw $\varepsilon$ from a uniform distribution in $[0,1]$. Randomly choose $j^{\text {th }}$ and $k^{\text {th }}$ flower among all the solutions and do local pollination through equation (11), end if;

V. Step 5: Evaluate new solutions using the objective function. If new solutions are better, update them in the population, end for,

VI. Step 6: Find the current best solution $g$ based on the objective fitness value, end while.

\section{MODELLING OF PDFF CONTROLLER}

In $\mathrm{PI}$ controller $\mathrm{K}_{\mathrm{P}}$ provides stability and high frequency response and $K_{1}$ ensures that the average error is driven to zero. So no long term error, as the two gains are tuned. (Figure 4)

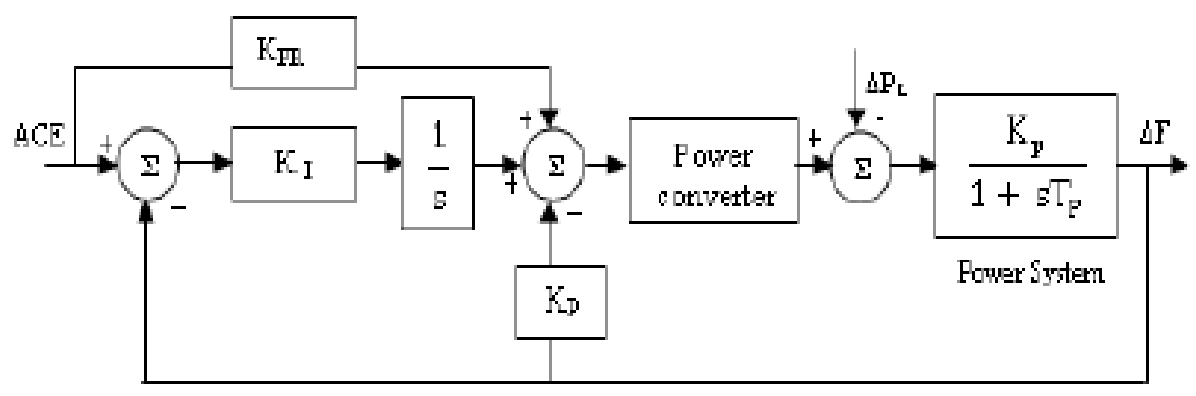

Figure 4: Block diagram for PDFF control. 
Case 1: The Power System Restoration Index 1 [19] $\left(P S R l_{1}\right)$ is obtained from the ratio between the settling time of the control input deviation $\Delta P_{c 1}\left(\tau_{s 1}\right)$ response of area 1 and power system time constant $\left(T_{p 1}\right)$ of area 1.

$\operatorname{PSRI}_{1}=\frac{\Delta P_{c 1}\left(\tau_{s 1}\right)}{T_{p 1}}$

Case 2: The Power System Restoration Index 2 $\left(\mathrm{PSRI}_{2}\right)$ is obtained from the ratio between the settling time of the control input deviation $\Delta P_{c 2}\left(\tau_{s 2}\right)$ response of area 2 and power system time constant $\left(T_{p 2}\right)$ of area 2.

$$
\operatorname{PSRI}_{2}=\frac{\Delta P_{c 2}\left(\tau_{s 2}\right)}{T_{p 2}}
$$

Case 3: The Power System Restoration Index 3 $\left(\mathrm{PSRI}_{3}\right)$ is obtained from the peak value of the control input deviation $\Delta P_{c 1}\left(\tau_{p}\right)$ response of area 1 with respect to the final value $\Delta P_{c 1}\left(\tau_{s}\right)$;

$$
\operatorname{PSRI}_{3}=\Delta P_{c 1}\left(\tau_{p}\right)-\Delta P_{c 1}\left(\tau_{s}\right)
$$

Case 4: The Power System Restoration Index 4 $\left(\mathrm{PSRI}_{4}\right)$ is obtained from the peak value of the control input deviation $\Delta P_{c 2}\left(\tau_{p}\right)$ response of area 1 with respect to the final value $\Delta P_{c 1}\left(\tau_{s}\right)$; (Figure $\mathbf{5}$ and $\mathbf{6}$ )

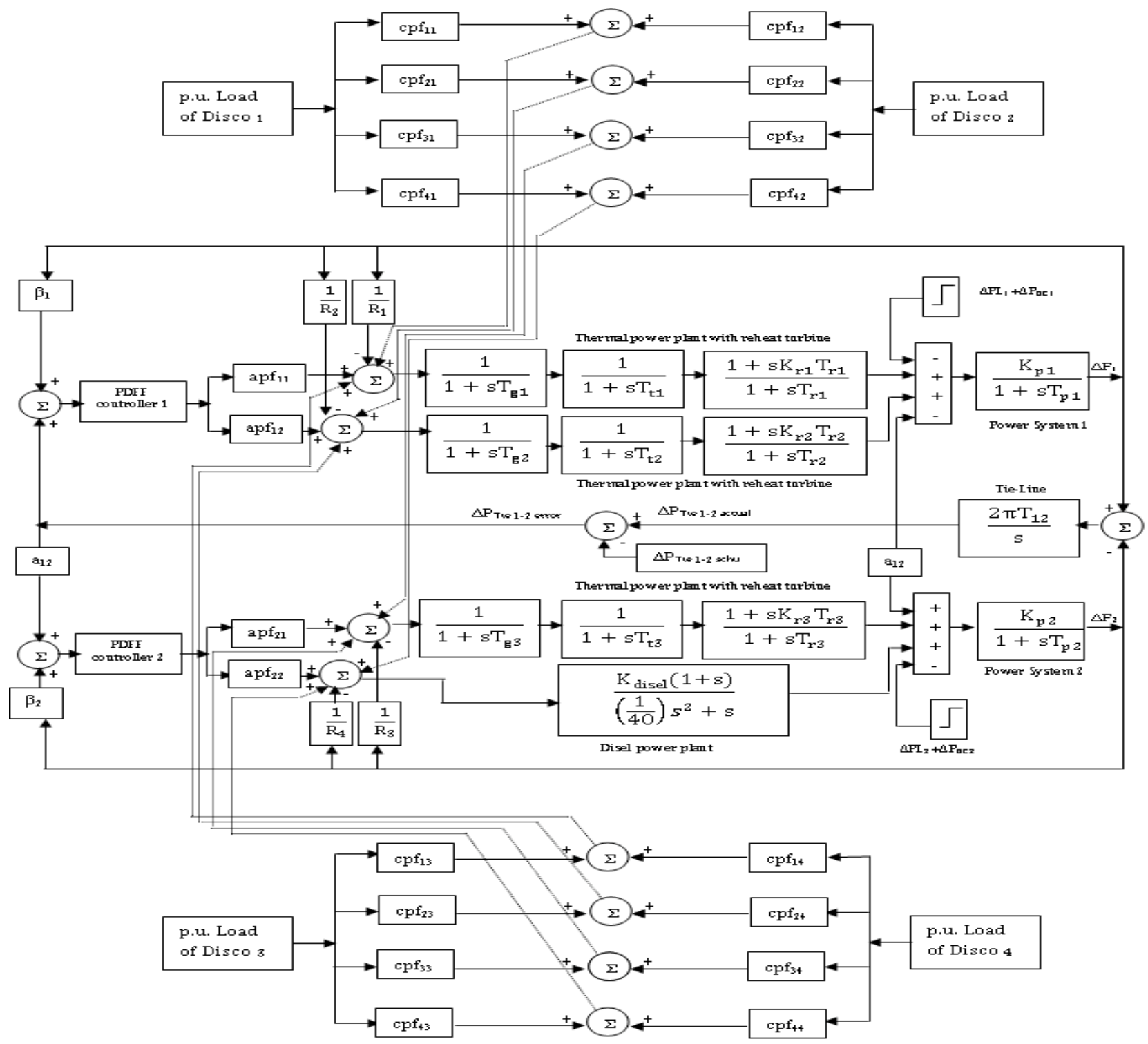

Figure 5: Linearized model of a two-area thermal-diesel interconnected power system in a restructured environment. 


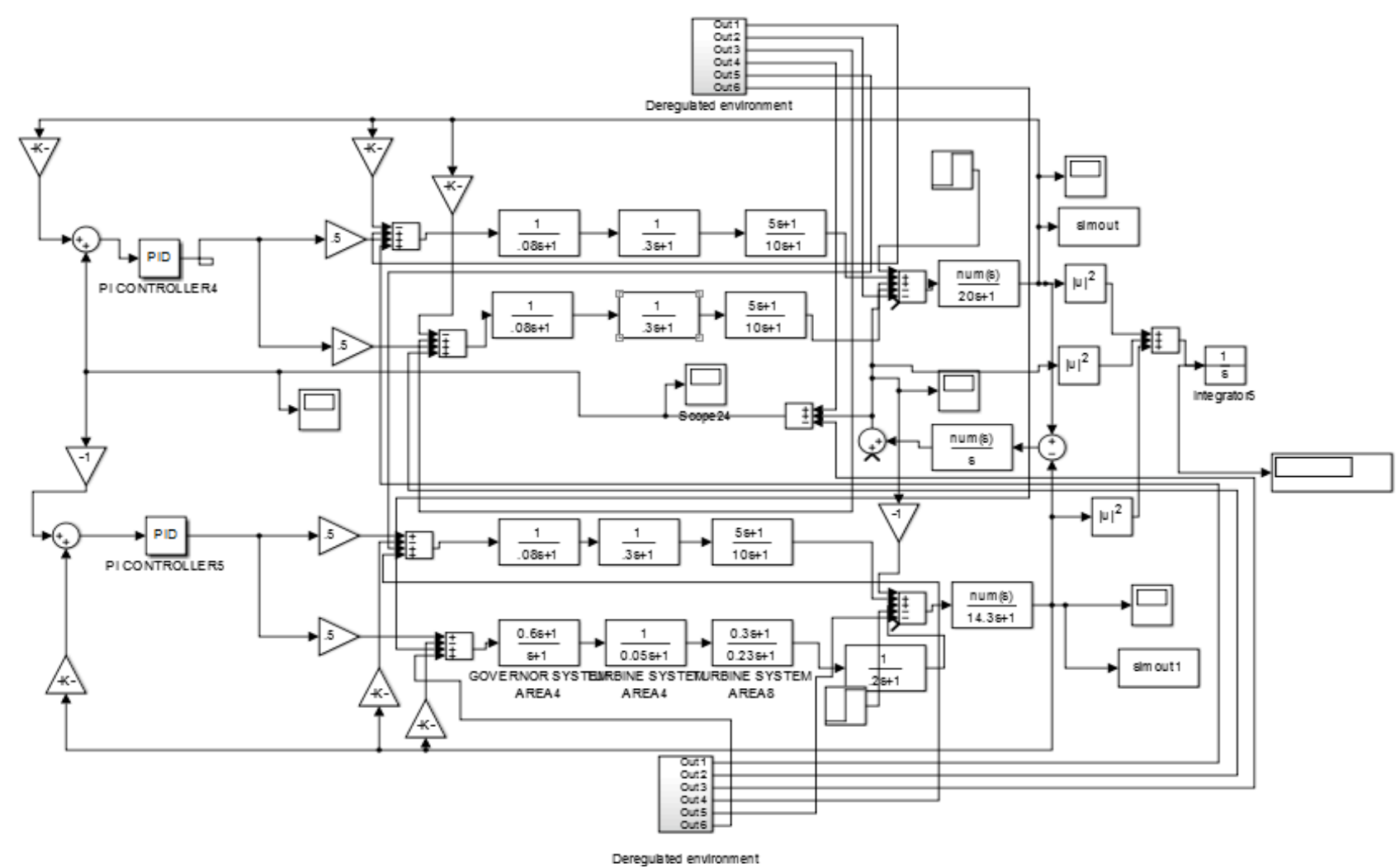

Figure 6: Simulation Diagram of Load-Frequency Controller for Deregulated Thermal-Heavy duty gas turbine Power Systems.

$$
\operatorname{PSRI}_{4}=\Delta P_{c 2}\left(\tau_{p}\right)-\Delta P_{c 2}\left(\tau_{s}\right)
$$

Table 1: Data for the Interconnected Two-Area Thermal power system [7]

\begin{tabular}{|c|c|}
\hline Rating of each area & $2000 \mathrm{MW}$ \\
\hline Base power & 2000 MVA \\
\hline Frequency & $60 \mathrm{~Hz}$ \\
\hline Power System gain & $\begin{array}{c}K_{P i}=120 \mathrm{~Hz} / \mathrm{p} . \mathrm{u} \\
\mathrm{MW}\end{array}$ \\
\hline Power system time constant & $T_{P i}=20 \mathrm{~s}$ \\
\hline $\begin{array}{l}\text { Speed regulation coefficient of each } \\
\text { area }\end{array}$ & $R_{i}=2.4 \mathrm{~Hz} /$ p.u MW \\
\hline Generator time constant & $T_{g i}=0.08 \mathrm{~s}$ \\
\hline Turbine time constant & $T_{t i}=0.3 \mathrm{~s}$ \\
\hline Frequency bias coefficient & $\beta_{i}=0.425$ p.u MW/Hz \\
\hline
\end{tabular}

Table 2: Data for Heavy Duty Gas Turbine unit [11]

\begin{tabular}{|c|}
\hline$b_{G}=0.049 \mathrm{sec}$ \\
\hline$C_{S}=1 \mathrm{Farad}$ \\
\hline$T_{C R}=0.01 \mathrm{sec}$ \\
\hline$T_{F}=0.239 \mathrm{sec}$ \\
\hline$T_{C D}=0.2 \mathrm{sec}$ \\
\hline
\end{tabular}

Table 3: Data for Diesel Unit [10]

\begin{tabular}{|c|}
\hline Diesel Unit \\
\hline \hline $\mathrm{K}_{\text {diesel }}=16.5$ \\
\hline$X_{G}=0.6 \mathrm{sec}$ \\
\hline$Y_{G}=1.1 \mathrm{sec}$ \\
\hline
\end{tabular}

Table 4: Optimized Gain Values of the PDFF Controller Using FPA for the Interconnected Power System

\begin{tabular}{|c|c|c|}
\hline \multirow{2}{*}{ Plant } & \multicolumn{2}{|c|}{ Gain Values } \\
\cline { 2 - 3 } & $\mathbf{K}_{\mathbf{P}}$ & $\mathbf{K}_{\mathbf{~}}$ \\
\hline \hline $\begin{array}{c}\text { Thermal - Thermal RPS without } \\
\text { HDGT / Diesel unit }\end{array}$ & 0.352 & 0.3504 \\
\hline $\begin{array}{c}\text { Thermal - Thermal RPS with } \\
\text { HDGT unit }\end{array}$ & 0.348 & 0.1585 \\
\hline $\begin{array}{c}\text { Thermal - Thermal RPS with } \\
\text { Diesel unit }\end{array}$ & 0.3678 & 0.4325 \\
\hline
\end{tabular}

\section{SIMULATION RESULTS AND DISCUSSIONS}

The simulation results obtained shown in Table 1 using Flower Pollination Algorithm reveals that the 
Table 5: PSRI for a Two-Area Interconnected Power System using FPA Based PDFF Controller Considering Gas I Diesel Power Plant

\begin{tabular}{|c|c|c|c|c|c|c|c|c|c|c|}
\hline \multirow[t]{2}{*}{$\begin{array}{l}\text { Load demand } \\
\text { change }\end{array}$} & \multicolumn{5}{|c|}{ 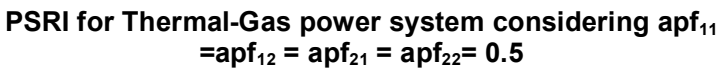 } & \multicolumn{5}{|c|}{ 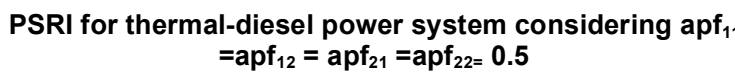 } \\
\hline & $\mathrm{PSRI}_{1}$ & $\mathrm{PSRI}_{2}$ & $\mathrm{PSRI}_{3}$ & $\mathrm{PSRI}_{4}$ & $\int P_{c 2}$ & $\mathrm{PSRI}_{1}$ & $\mathrm{PSRI}_{2}$ & $\mathrm{PSRI}_{3}$ & $\mathrm{PSRI}_{4}$ & $\int P_{c 2}$ \\
\hline Case 1 & 1.623 & 1.320 & 0.097 & 0.041 & 0.253 & 1.488 & 1.501 & 0.091 & 0.020 & 0.139 \\
\hline Case 2 & 1.75 & 1.715 & 0.111 & 0.038 & 0.348 & 1.741 & 1.524 & 0.121 & 0.034 & 0.214 \\
\hline Case 3 & 1.721 & 1.678 & 0.096 & 0.039 & 3.484 & 1.691 & 1.58 & 0.081 & 0.012 & 3.346 \\
\hline Case 4 & 2.252 & 2.145 & 0.129 & 0.049 & 3.923 & 2.123 & 2.021 & 0.131 & 0.028 & 3.742 \\
\hline
\end{tabular}

dynamic response of the system of the two-area interconnected Restructured Power System (RPS) with HDGT ensures a better dynamic response than that of the RPS without HDGT unit. Integral square Error (ISE) technique is used to obtain the optimum PID-controller gains. (Figure 7-11)

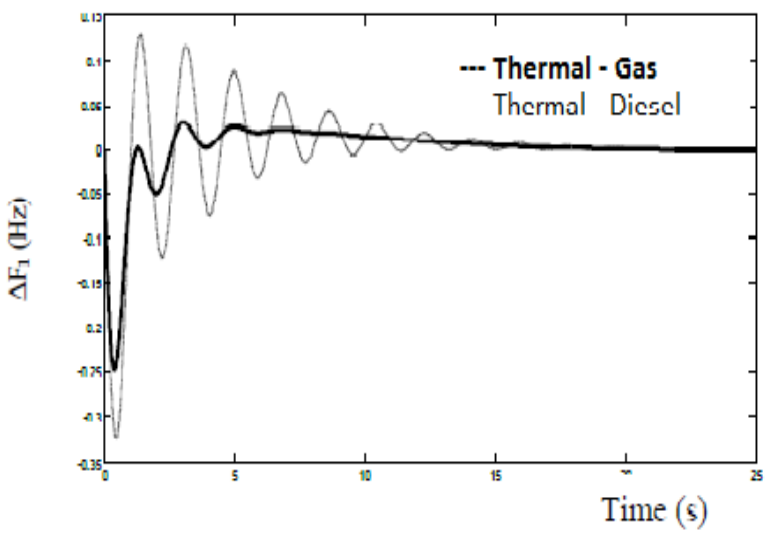

Figure 7: $\Delta \mathrm{F}_{1}(\mathrm{~Hz})$ vs Time (s).

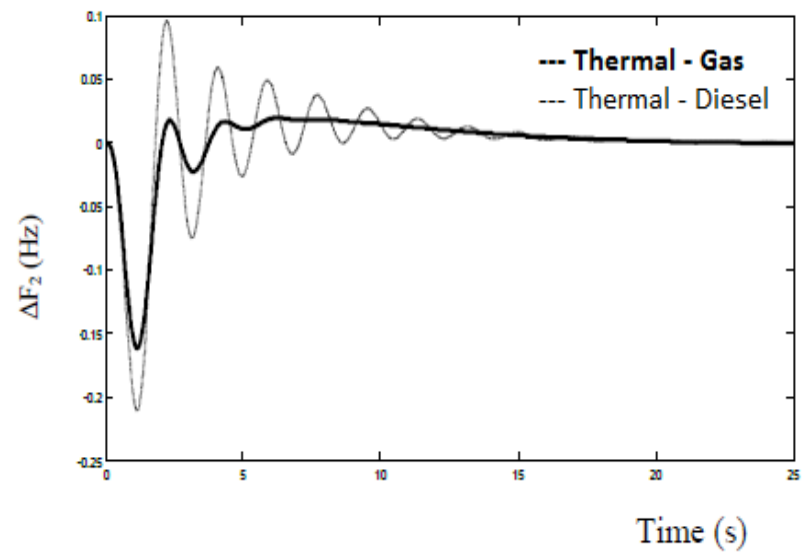

Figure 8: $\Delta \mathrm{F}_{2}(\mathrm{~Hz})$ vs Time (s)

\section{CONCLUSION}

This paper proposes the design of various Power System Ancillary Service Requirement Assessment Indices (PSASRAI) which highlights the necessary requirements to be adopted in minimizing the control input deviations there by reducing the frequency deviations, tie-line power deviation in a two-area

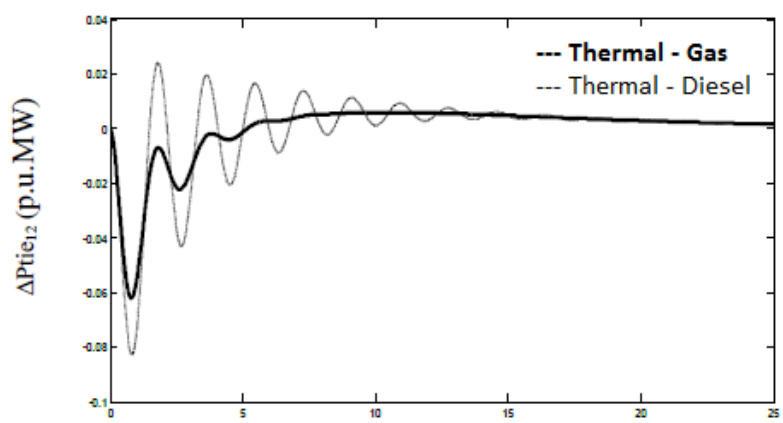

Time (s)

Figure 9: $\Delta \mathrm{P}_{\text {tie }}($ p.u. MW) vs Time (s)

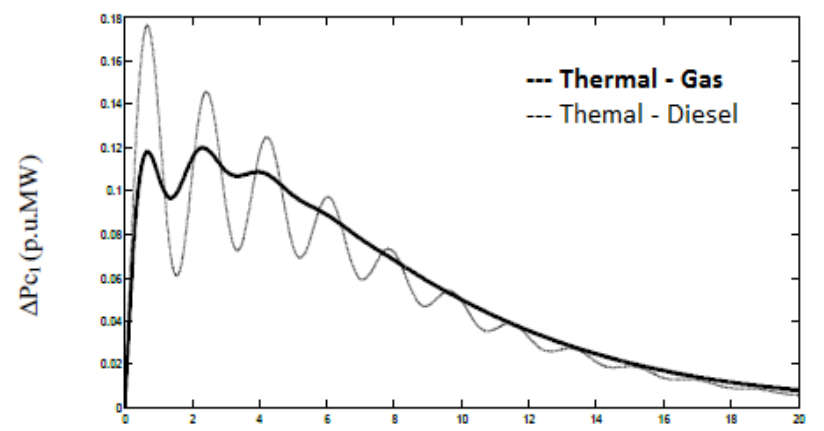

Time (s)

Figure 10: $\Delta \mathrm{P}_{\mathrm{c1}}$ (p.u. MW) vs Time (s). 


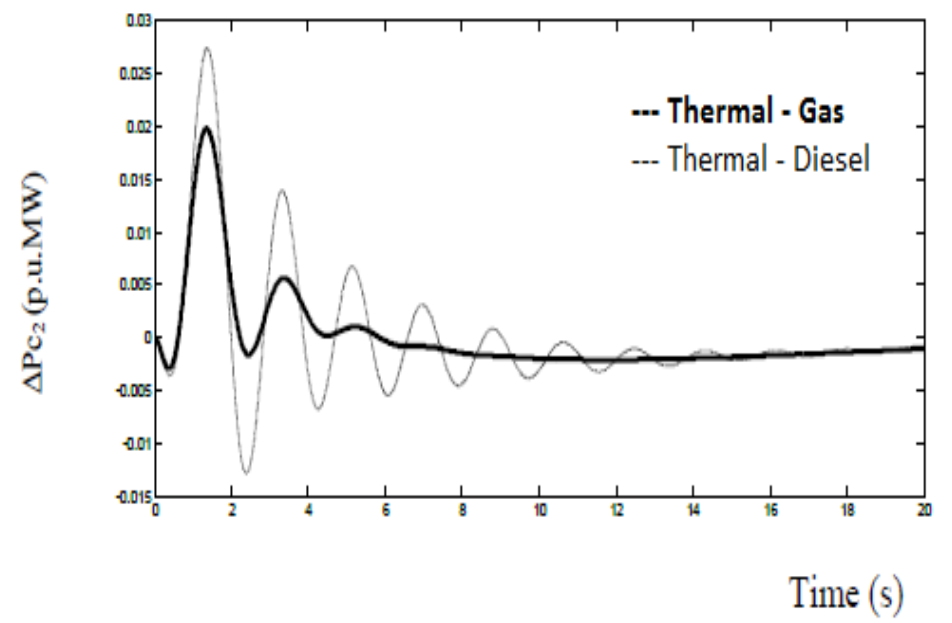

Figure 11: $\Delta \mathrm{P}_{\mathrm{c} 2}$ (p.u. MW) vs Time (s).

Thermal reheat interconnected restructured power system to ensure the reliable operation of the power system. The PDFF controllers are designed using FPA algorithm and implemented in a TATRIPS unit. This FPA Algorithm was employed to achieve the optimal parameters of gain values of the various combined control strategies. As FPA is easy to implement without additional computational complexity, with this algorithm quite promising results can be obtained and ability to jump out the local optima. Moreover, Power flow control is also found to be efficient and effective for improving the dynamic performance of load frequency control of the interconnected power system than that of the system. From the simulated results it is observed that the restoration indices calculated for the TATRIPS with SMES unit indicates that more sophisticated control for a better restoration of the power system output responses and to ensure improved Power System Ancillary Service Requirement Assessment Indices (PSASRAI) in order to provide good margin of stability.

\section{REFERENCES}

[1] Shashi Kant Pandey, Soumya R Mohanty and NandKishor. A literature survey on load-frequency control for conventional and distribution generation power systems. Renewable and Sustainable Energy Reviews Renewable and Sustainable Energy Reviews 2013; 25: 318-334. https://doi.org/10.1016/j.rser.2013.04.029

[2] Singh Parmar KP, Majhi S and Kothari DP. Load frequency control of a realistic power system with multi-source power generation. Electrical Power and Energy Systems 2012; 42: 426-433.

https://doi.org/10.1016/j.ijepes.2012.04.040

[3] Dong L, Zhang $Y$ and Gao Z. A robust decentralized load frequency controller for interconnected power systems. ISA Transaction 2012; 51: 410-419. https://doi.org/10.1016/j.isatra.2012.02.004
[4] Sivachandran P, Lakshmi D and Amalrajan R. A Study on Load Frequency Control. Middle-East Journal of Scientific Research 2016; 24(3): 740-749.

[5] Mukta and Balwinder Singh Surjan. Load Frequency Control of Interconnected Power System in Deregulated Environment: A Literature Review. International Journal of Engineering and Advanced Technology (IJEAT) ISSN: 22498958; 2013; 2(3): 435-441.

[6] Ibraheem and Omveer Singh. Current Philosophies of Intelligent Techniques based AGC for Interconnected Power Systems. International Journal of Energy Engineering (IJEE) 2014; 4(4): 141-150.

[7] Velusami S and Chidambaram IA. Decentralized Biased dual mode controllers for Load-frequency control of interconnected power system. Electric Power Components and Systems 2006; 34(10): 1057-1075.

https://doi.org/10.1080/15325000600630327

[8] Sadia Firdous and Mohammed Abdul Rahman Uzair. Load Frequency Control Techniques. International Journal of Science. Engineering and Technology Research (IJSETR) 2015; 4(8): 2887-2893.

[9] Chatterjee, Ghoshal SP and Mukherjee V. Transient Performance Improvement of Thermal System Connected to Grid Using Distributed Generation and Capacitive Energy Storage Unit. International Journal on Electrical Engineering and Informatics 2010; 2(3): 159-178. https://doi.org/10.15676/ijeei.2010.2.3.1

[10] Ramakrishna KSS, Pawan Sharma and Bhatti TS. Automatic generation control of interconnected power system with diverse sources of power generation. International Journal of Engineering, Science and Technology 2010; 2(5): 51-65. https://doi.org/10.4314/ijest.v2i5.60102

[11] Soon Kiat Yee, Jovica $V$ Milanovic and Michael Hughes F. Overview and Comparative Analysis of Gas Turbine Models for System Stability Studies. IEEE Transactions on Power Systems 2008; 23(1): 108-118.

https://doi.org/10.1109/TPWRS.2007.907384

[12] Hajagos LM and Berube GR. Utility Experience with Gas Turbine Testing and Modeling. IEEE Transactions on Power Engineering Society, Winter Meeting 2001; 2: 671-677. https://doi.org/10.1109/PESW.2001.916934

[13] Yang XS. Flower pollination algorithm for global optimization. Berlin Heidelberg: Springer 2012. https://doi.org/10.1007/978-3-642-32894-7 27

[14] Yang XS, Karamanoglu $M$ and $\mathrm{He} X$. Flower pollination algorithm: a novel approach for multi objective optimization. Engineering Optimization 2014; 46(9): 1222-1237. https://doi.org/10.1080/0305215X.2013.832237 
[15] Yang XS. Flower pollination algorithm for global optimization, in: Unconventional Computation and Natural Computation. Lecture Notes in Computer Science 2012; 7445: 240-249. https://doi.org/10.1007/978-3-642-32894-7 27

[16] Mohamed Abdel-Baset and Ibrahim M Hezam. An Effective Hybrid Flower Pollination and Genetic Algorithm for Constrained Optimization Problems. International Journal Advanced Engineering Technology and Application 2005; 3: 27-34.

[17] ManMehak Sidhu and Shivani Mehta. Pollination Based Optimization for Economic Load Dispatch Problem. International Journal of Research in Advent Technology 2015; 3(4): 27-36.
[18] Kirandeep Kaur, Khushal Thakur and Anmol Goyal. Flower Pollination Algorithm (FPA) Optimization based Multiuser Detection for DS-UWB Communication System. International Journal of Research in Electronics and Computer Engineering (IJRECE) 2015; 3(2): 159-164.

[19] Chidambaram IA and Sridhar ND. Computation of Ancillary Service Requirement Assessment Indices for Load Frequency Control in a Restructured Power System using SMES Unit and SCES Unit. Global Journal of Energy Technology Research Updates 2014; 1(1): 1-15.

Received on 29-11-2017

Accepted on 11-12-2017

Published on 31-12-2017

DOI: http://dx.doi.org/10.15377/2409-5818.2017.04.3

(C) 2017 Subramanian, et al.; Avanti Publishers.

This is an open access article licensed under the terms of the Creative Commons Attribution Non-Commercial License (http://creativecommons.org/licenses/by-nc/3.0/) which permits unrestricted, non-commercial use, distribution and reproduction in any medium, provided the work is properly cited. 